\title{
Measuring workplace bullying
}

\author{
Helen Cowie ${ }^{\mathrm{a}, *}$, Paul Naylor ${ }^{\mathrm{a}}$, Ian Rivers ${ }^{\mathrm{b}}$, Peter K. Smith ${ }^{\mathrm{c}}$, Beatriz Pereira ${ }^{\mathrm{d}}$ \\ ${ }^{a}$ School of Psychology and Counseling, University of Surrey Roehampton, West Hill, London SW15 3SN, UK \\ ${ }^{\mathrm{b}}$ College of Ripon and York St John, North Yorkshire, UK \\ ${ }^{\mathrm{c}}$ Goldsmiths College University of London, London, UK \\ ${ }^{\mathrm{d}}$ University of Minho, Spain
}

Received 29 November 1999; received in revised form 7 July 2000; accepted 31 July 2000

\begin{abstract}
Workplace bullying is increasingly being recognized as a serious problem in society today; it is also a problem that can be difficult to define and evaluate accurately. Research in this area has been hampered by lack of appropriate measurement techniques. Social scientists can play a key part in tackling the phenomenon of workplace bullying by developing and applying a range of research methods to capture its nature and incidence in a range of contexts. We review current methods of research into the phenomenon of bullying in the workplace. We examine definitional issues, including the type, frequency, and duration of bullying acts, and consider the role of values and norms of the workplace culture in influencing perception and measurement of bullying behavior. We distinguish methods that focus on: (a) inside perspectives on the experience of bullying (including questionnaires and surveys, self-report through diary-keeping, personal accounts through interviews, focus groups and critical incident technique, and projective techniques such as bubble dialogue); (b) outside perspectives (including observational methods and peer nominations); (c) multi-method approaches that integrate both inside and outside perspectives (including case studies). We suggest that multi-method approaches may offer a useful way forward for researchers and for practitioners anxious to assess and tackle the problem of bullying in their organizations. (C) 2001 Elsevier Science Ltd. All rights reserved.
\end{abstract}

Keywords: Adult bullying; Bullying in the workplace; Aggression; Measurement

* Corresponding author. Tel.: +44-20-8392-3510; fax: +44-20-8392-3610.

E-mail address: h.cowie@roehampton.ac.uk (H. Cowie). 


\section{What is workplace bullying?}

Bullying is usually defined as a subset of aggressive behavior, in which the aggression is repeated, and in which there is an imbalance of power such that it is difficult for the victim to defend him/herself (Olweus, 1999). Although traditionally applied in school contexts, adult bullying, specifically bullying in the workplace, has begun to be systematically studied in the last 5 years in Scandinavia (Björkqvist et al., 1994; Björkqvist et al., 1994; Einarsen \& Raknes, 1991, 1997; Einarsen \& Skogstad, 1996; Leymann, 1990, 1996), in Germany and Austria (Niedl, 1995, 1996; Zapf et al., 1996), in Portugal (Almeida, 1992; Lima et al., 1994; Monteiro, 1993; Sousa \& Vala, 1999; Theotónio \& Vala, 1999), in the UK (Adams, 1992; Cowie et al., 1999; Crawford, 1997; Lewis, 1999; Quine, 1999; Rayner, 1997; Rayner \& Höel, 1997), and in the USA (Baron et al., 1999; Brodsky, 1977; Keashley et al., 1994). There are similarities and differences in comparison with the phenomenon as it appears in school contexts (Schuster, 1996; Smith, 1997), but the issue of workplace bullying presents particular methodological challenges.

Bullying has now become identified as a serious issue in the workplace context. In many countries, trade unions, professional organizations, and human resources (HR) departments have become more aware over the last decade that behaviors such as intimidation, public humiliation, offensive name-calling, social exclusion, and unwanted physical contact has the potential to undermine the integrity and confidence of employees and reduce efficiency. People who have been bullied report that it affects them physically and mentally, with stress, depression, and lowered self-esteem as the most common complaints. In extreme cases, bullied employees may require counseling or psychiatric treatment (Niedl, 1996).

Bullying may go beyond colleague-on-colleague abuse and become an accepted, or even encouraged, aspect of the culture of an organization. A number of organizations now recognize the need to change the culture of the workplace and have developed clear company policies to offer protection from bullying to their employees.

In this article, we first examine definitional issues, and then review a range of methods of assessing workplace bullying, ending with recommendations for future research in this area.

\section{Definitional issues}

\subsection{Types of bullying}

In an earlier overview of research, Rayner and Höel (1997) grouped workplace bullying behaviors into the following types:

- threat to professional status (e.g., belittling opinion, public professional humiliation, and accusation regarding lack of effort);

- threat to personal standing (e.g., name-calling, insults, intimidation, and devaluing with reference to age); 
- isolation (e.g., preventing access to opportunities, physical or social isolation, and withholding of information);

- overwork (e.g., undue pressure, impossible deadlines, and unnecessary disruptions)

- destabilization (e.g., failure to give credit when due, meaningless tasks, removal of responsibility, repeated reminders of blunders, and setting up to fail).

It may also be useful to include the concepts of 'relational bullying' (Crick \& Grotpeter, 1995), in which the bully damages the victim's friendship networks, and 'indirect bullying' (Björkqvist et al., 1994) perpetrated by a third party, such as rumor spreading. Relational bullying and indirect bullying have in common the expression of social manipulation, and can often go unnoticed by others. It can therefore be particularly difficult for the victims to report on their experiences, or to be believed if they do. Factor analyses of questionnaire items have generally yielded some five or six factors, covering concepts similar to those cited by Rayner and Höel but including social isolation and rumors (Zapf, 1999; and see Section 3.1 on questionnaires).

Bullying in the workplace is in some ways similar to bullying in other situations, for example in schools. Both in the school and in the workplace, factors of organizational climate and working arrangements can contribute to the incidence of bullying; for example, the existence and effectiveness of an anti-bullying policy in schools and quality of working environment in the workplace. However, individual factors are also likely to be important in both school and workplace contexts. These include low self-esteem, disability, physical weakness, shyness and unassertive or anxious personality, lack of friends, and social rejection (Coyne et al., 1999; Monks \& Smith, 2000). Methodologically, questionnaires used in research on school bullying have influenced those used in workplace bullying (Einarsen et al., 1994), but research in workplace bullying has, to a greater extent than the research on school bullying, used a range of other methodologies including focus groups, case studies, and more qualitative approaches (Smith, 1997).

Bullying is generally taken to refer to negative acts directed at a person as an individual; but negative acts can be construed as being related to more general constructs such as gender, or ethnic group; in such cases, terms such as sexual harassment or racial harassment may be used. The distinction is not easy to draw, and many researchers in this field argue that bullying and other forms of harassment, for example sexual and racial harassment, are related (Fitzgerald et al., 1997; Rayner \& Höel, 1997). However, the majority of research studies in the area (for example, the questionnaire inventories) have focused on interpersonal bullying rather than on harassment specifically of a racial or sexual nature.

\subsection{Frequency and duration of bullying}

While some degree of repetition is usually thought to characterize bullying, there is no agreement on the extent of frequency and duration needed to define it. Anecdotal accounts (Adams, 1992; Randall, 1997) indicate the belief that a colleague can bully another person without demonstrating regular behavior, for example through even a single threatening act. However, Einarsen and Skogstad (1996) consider that behaviors that have taken place within the last 6 months 'now and then' or 'weekly' can be defined as bullying. More stringently, 
Leymann (1990) suggested a criterion with regard to frequency as being around one incident per week over a period of at least 6 months. Björkqvist, Österman, and Hjelt-Bäck, 1994 investigate persistent behaviors within the past year (see Höel et al., 1999 for a further review of these criteria).

\subsection{Imbalance of power}

Some imbalance of power is usually thought to characterize bullying. Einarsen and Skogstad (1996, p. 187) argue that a person is bullied if he or she is repeatedly subjected to negative acts in the workplace, adding that 'to be a victim of such bullying one must also feel inferiority in defending oneself in the actual situation.' This means that they do not limit their definition of bullying to a set of 'objectively' predefined negative acts; furthermore, they invoke the subjective experience of the victim. Who decides whether there is an imbalance of power? Einarsen and his colleagues and Rayner and Höel (1997) particularly focus on the victims' perspectives and experiences of the phenomenon of bullying. The measurement of internal and external perspectives on the phenomenon, including the reactions of the victims, their perceived power in relation to the perpetrator, the intent of the perpetrator and the social/ organizational contexts in which bullying takes place, are vital considerations in measuring workplace bullying.

\subsection{Inside and outside perspectives}

The debate over 'objective' and 'subjective' data collection is not new in this field. In his pioneering study of workplace harassment in the USA, Brodsky (1977), a doctor on the California Workers' Compensation Appeals Board, identified bullying as "repeated and persistent attempts by one person to torment, wear down, frustrate or get a reaction from another." He distinguished between subjective forms of harassment (as experienced by the victim) and objective forms (behavior that breached agreed criteria of acceptable behavior).

Researchers in the field disagree about the reliability and validity of self-reports on the part of victims, that is the inside perspective on the phenomenon of the bullied person. A major difficulty is that there is little evidence of the accuracy or stability of participants' recollections or reports across time. Some studies have addressed the issue by examining the stability of victims' memories of being bullied. In a retrospective study of the experiences of a sample of 60 lesbians, gay men, and bisexual men and women bullied at school, Rivers (1999) found that participants' memories of bullying remained stable over a 12-14-month period. In his longitudinal study of bullying, Olweus (1993) noted that participants' recollections of bullying at age 23 were closely allied to the behaviors they reported at age 16. In addition, their estimates of the severity of the bullying they experienced at school were also found to be relatively accurate when compared to peer nominations at age 16. Having said that, very little evidence of peer verification (that is, witness statements) of incidents of aggression tends to be reported in the literature, and similarly, apart from Rivers' study, there is little evidence of any attempt to measure test-retest reliability when data are collected retrospectively. Up to this point, there have been very few systemic studies of bullying in its social context. Furthermore, there are practical and ethical difficulties about identifying who 
the bullies are and why they engage in such behavior, yet their perspective too is a valid one. Consequently, many researchers are reluctant to rely solely on personal accounts by victims.

Liefooghe and Olafsson (1999) have argued that it is possible to view bullying as a set of events that can be conceptualized in many ways rather than as an 'objective' reality. They recommend that researchers in this field explore a range of representations of bullying in order to have a flexible, multi-faceted view of workplace bullying that encompasses the individual employee and the broader perspectives of the organization. Höel et al. (1999) consider that the subjectivity-objectivity debate has a key role to play in the development of research in this field. For example, the source of apparently objective items (such as, in the Leymann Inventory of Psychological Terrorization (LIPT), see Section 3.1) lies in in-depth interviews with victims and so may be emotionally loaded. They argue that one solution may be to devise research instruments with 'neutrally worded items' in order to reduce the influence of cognitive and emotional processes on the part of respondents.

\subsection{Values and norms of the workplace}

The values and norms of the workplace influence how bullying is defined in that context, how employees interpret situations (for example, as 'bullying' or 'firm management'), and whether bullying is recognized as a problem. Einarsen and his colleagues (e.g., Einarsen \& Raknes, 1991; Einarsen \& Skogstad, 1996) view the culture of the workplace as a form of filter through which behaviors are interpreted and through which a range of behaviors is accepted or tolerated. On the basis of their investigations in male-dominated industries, they argue that knowledge of the value placed at all levels of a company on such concepts as 'machismo/masculinity' or 'efficiency at all costs' will enhance the researcher's understanding of workplace relationships and the tolerance, or otherwise, of aggressive behavior.

Sheehan (1998) discusses the impact on the cultural values of an organization when major restructuring, for example downsizing, takes place. He highlights negative outcomes (including organizational bullying) that suggest variance between the 'rhetoric of restructuring' as expressed by managers and the 'brutal reality' as experienced by employees.

Sousa and Vala (1999), in a study about organizational culture, conclude that where management is perceived as fair - in other words, where the predominant set of values in the workplace includes the concept of justice - employees are more receptive to change and are more open in their relationships towards one another. Theotónio and Vala (1999) investigated employees' perceptions of justice and injustice in organizational contexts. Workers were asked to describe a situation in which they felt unjustly treated by a superior or describe a personal episode of injustice in the organization of work. Then, they were invited to describe what would have made this episode a just situation. Injustice episodes were structured around distributive dimensions, while justice claims were structured around procedural and interactional dimensions. The authors draw out the influence of organizational culture in the way in which justice and injustice are construed by workers, so adding a useful dimension to the debate around whether the focus of assessment should be on subjective or objective forms of bullying.

From these studies, it would appear that the climate of the organization can have a strong influence on the ways in which bullying is defined, identified, and assessed. The debate 
indicates the need to explore the issue of workplace bullying at different levels, from individual to organizational. There are subjective and objective aspects to be taken account of, as well as individual, social, and cultural aspects.

In the main section of the article, we summarize a range of measures used in the research literature on workplace bullying. We review these measures of workplace bullying under three headings: (1) those that focus on inside perspectives (including questionnaires and surveys, self-report through diary-keeping, personal accounts through interviews, focus groups and critical incident technique (CIT), and projective techniques such as bubble dialogue), (2) those that focus on outside perspectives (including observational methods and peer nominations), and (3) multi-modal approaches that attempt to integrate perspectives and triangulate measures.

\section{Measures of workplace bullying 1: inside perspectives on the experience of bullying}

\subsection{Questionnaires and surveys}

Questionnaires have been the predominant method used in large-scale survey work, and most take the form of self-report questionnaires. A number of instruments of varying complexity have been devised. At its simplest, a survey may simply ask whether the respondent has experienced an event of workplace bullying (Lewis, 1999), with yes/no response. Einarsen and Skogstad (1996) gave a written definition of bullying, and asked the respondent whether he/she had been subjected to bullying at the workplace over the last 6 months, with a 5- or 7-point frequency scale for response; in addition, asking about duration, number, sex, and position of the perpetrators.

However, more elaborate questionnaires have been developed. Perhaps, the most extensively used have been forms of the LIPT. Leymann (1990) developed this in Swedish, but a revised version (LIPT-II) has been widely used in a German translation (Niedl, 1996; Zapf et al., 1996). The questionnaire consists of 45 , or (revised version) 46 , items representing various bullying actions, e.g., attacking a person's possibilities of communication, attacking a person's social relationships, attacking a person's social reputation, attacking the quality of a person's occupational and life situation, and attacking a person's health. Each item is scored on frequency of occurrence; the scales used have varied in different studies: a 3- or 4-point scale in Zapf et al. (1996), a 6-point scale in Niedl (1996). Niedl also included a 6-point scale for duration of each item; plus, a general question on number, position, and sex of aggressors. Since the LIPT measures defined acts, it is not usually considered necessary to give a definition of bullying; but Vartia (1996) did precede its use with a written definition in his questionnaire.

The LIPT has been factor-analyzed by Leymann (1990); Neidl (1995), and Zapf et al. (1996) with similar, though not identical, results. Leymann (1996) found factors labeled as negative communication, humiliating behavior, isolating behavior, frequent changes of task to punish someone, and violence or threat of violence. Niedl identified seven factors: attacking a person's integrity, isolation, direct and indirect critique, sanction by certain tasks, threats, sexual encroachment, and attacking a person's private sphere. Zapf et al. also identified seven 
factors, and reports reliability (Cronbach's $\alpha$ ) from two samples, for each scale, as follows: attacks with organizational measures $(0.79,0.86)$, social isolation $(0.84,0.83)$, attacking private life $(0.73,0.75)$, physical violence $(0.40,0.69)$, attacking attitudes $(0.52,0.63)$, verbal aggression $(0.57,0.66)$, and rumors $(0.71,0.65)$. Zapf et al. modified the LIPT into six scales (omitting 'attacking attitudes' due to low occurrence); he reported reliability for each scale, as follows: organizational measures (0.92), social isolation (0.81), attacking private life (0.74), physical violence $(0.54)$, attacking attitudes, and rumors $(0.70)$.

Einarsen and Raknes (1997) developed the Negative Acts Questionnaire (NAQ) in a study of harassment in the workplace. The questionnaire consists of 22 items, each written in behavioral terms with no reference to terms such as bullying or harassment. The NAQ was derived from two distinct sources of information - literature studies and accounts given by victims of long lasting harassment. The scale measures how often (5-point scale) the respondent has been subjected to a range of negative acts and potentially harassing behaviors during the last 6 months. Factor analysis of the NAQ by Niedl (1995) elicited the following factors: attacking the private person, social isolation, work-related measures, and physical violence.

Einarsen and Raknes (1997) obtained three main factors, with reliability (Cronbach's $\alpha$ ) for each scale, as follows: personal derogation (0.85), work-related harassment (0.57), social exclusion (0.33); plus two items on social control and one on physical abuse. Einarsen and Raknes also suggest evidence for validity, in that strong correlations were found between self-reported scores on the NAQ and general low scores (including those of non-victims) on work environment.

Björkqvist, Österman, and Hjelt-Bäck, 1994 developed the Work Harassment Scale (WHS) to study aggression among university employees. The questionnaire consists of 24 items, with reliability (Cronbach's $\alpha$ ) of 0.95 . Participants assess on a 5-point scale how often they have been exposed to 24 types of degrading and oppressing activities by their colleagues during the last 6 months. Items include: 'being unduly criticized,' 'being shouted at loudly,' 'being isolated,' and 'lies about you told to others.' Participants also indicate whether the aggressor is male or female. Björkqvist, Österman, and Lagerspetz (1994) reported a factor analysis of the WHS leading to two subscales of covert or disguised aggression, referred to as 'rational-appearing aggression' and 'social manipulation.' Rationalappearing aggression (Cronbach's $\alpha=0.70$ ) included such items as 'reduced opportunities to express oneself,' 'being interrupted,' 'having one's work judged in an unjust manner,' and 'being criticized.' Social manipulation (Cronbach's $\alpha=0.82$ ) included such items as 'insulting comments about one's private life,' 'backbiting,' 'spreading false rumors,' and 'not being spoken to.'

Baron et al. (1999) devised a questionnaire containing 40 items describing workplace aggression (e.g., 'staring, dirty looks, or other negative eye contact,' 'giving someone the silent treatment,' 'intentionally damning with faint praise,' and 'showing up late for meetings run by the target'). Each item rated for frequency on a 5-point scale. Reliability (Cronbach's

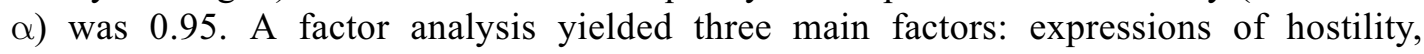
obstructionism, and overt aggression. In addition, a single item inquired about the frequency with which the respondent had engaged in aggression against various targets (supervisor, coworker, subordinate, etc.). 
Einarsen et al. (1994) describe the Bergen Bullying Index, which has five items scored on a 4-point scale of agreement (Cronbach's $\alpha=0.86$ ). This scale measures the extent to which the respondent sees bullying generally as an issue affecting them and others in the workplace.

In general, a choice between these questionnaires may be influenced by length and coverage; the LIPT has the largest number of items, greatest coverage, and acceptable reliabilities (apart from for physical violence, which has rather low incidence). Reliability for two scales of the NAQ is rather low, but for the other questionnaires reviewed, quite high. However, only the NAQ has independent evidence for validity (see above). Generally, the only evidence for validity of these questionnaires comes from correlations of self-reports on bullying with self-reports on other measures such as subjectively experienced stress and psychological health (Zapf et al., 1996), or depression, anxiety, and aggressiveness (Björkqvist et al., 1994), and such correlations are affected by shared method variance.

Mostly, questionnaires have developed measures for the experience of being a victim of bullying in the workplace; less well developed are measures of perpetrating bullying, or of witnessing bullying.

The advantages of the questionnaire method are that the researcher can collect large amounts of data in a relatively short space of time; also, anonymity of participants can be assured. It is easy to carry out statistical analysis of a range of factors, including gender, status, age; for example, Einarsen and Skogstad (1996) compared data from 14 different Norwegian surveys $(N=7986)$ and reported on the relation between rates of bullying and size of organization, as well as gender and power differences between bullies and victims.

However, there are disadvantages to questionnaires. If no definition is given and the questionnaire relies exclusively on the occurrence of negative or aggressive acts, it may not be clear that the imbalance of power criterion is satisfied. By contrast, if an operational definition is used, we cannot be sure if the respondents are using the researcher's definition or their own. Respondents may focus more on individuals and ignore the wider organizational culture. There may be difficulties in relying on memory for defined periods such as 6 months or a year. The questionnaire format makes it difficult to gain detailed information regarding the processes and dynamics of bully/victim situations. It is inflexible in its structure and thus non-responsive to the rich details of particular instances and to the possibilities of uncovering radically new findings.

\subsection{Self-report through systematic diary keeping}

People who are being bullied may not always report the matter and may only gradually become aware that their unhappiness is based in the experience of being bullied, particularly if the bullying is indirect or if the victim is being socially isolated or excluded (Crick \& Grotpeter, 1995). The process of responding to bullying episodes may be better understood if the bullied person is able to make regular records of their experiences. The UK Trades Union Congress (TUC) (1998) guidelines recommend that health and safety officers should encourage employees to record episodes of bullying (or suspected bullying) in a systematic, regular way so that there is an accurate record of what happened and a chronological order to events. The individual can be asked to record all the bullying events that occur - what 
happened, which persons were involved, when did it happen, did anyone observe/bystand or intervene - the feelings that were experienced, and the outcomes of the episode. At negotiated points in the diary-keeping process, the diary could form the basis of in-depth interviews with the diarist. However, this would rely on participants maintaining diaries over an extended period of time. Consequently, the dropout rate would be quite high without the researcher or employer providing some incentive.

The method of systematic diary-keeping is described by McGhee and Miell (1998) for gathering longitudinal data on everyday interactions that the respondent experienced during each day. Participants are asked to write down the three most significant interactions of each day in their own words, and to rate these interactions on a 7-point scale in terms of such variables as satisfaction, intimacy, similarity to the other person, liking, and empathy. The method could be adapted to provide detailed information on the quality of interactions among colleagues in a workplace.

The advantage of diaries is that the researcher gains access to real-life, authentic experiences. Since relationships are built up of numerous interactions among people, the diary method focuses on these individual exchanges and their place in the overall relationship, so it can identify patterns of behavior across time, and so can be used to identify the frequency and duration aspects of bullying. If a large sample of employees agreed to keep diaries, this would facilitate the exploration of the incidence and types of bullying. The scoring of data across respondents would enable inter-rater reliability assessments to be made. A disadvantage is the lack of comparability across diaries due to limited standardization of format. There is also the problem that the truth, or otherwise, of diary entries cannot often be verified. To date, this method has not been applied to the problem of bullying.

\subsection{Personal accounts elicited through interviews}

The face-to-face interview focuses on the complex ways in which participants in a social situation interpret and describe their world and the people in it. The researcher is both immersed in the interview situation and external to it. The well-designed interview study would normally fall into four stages: ice-breaking and building trust; progressive focussing on the issue; forming a tentative model; and the process of confirming or reforming the tentative model through the gathering of evidence. Grounded theory analysis takes this process further by allowing constructs to emerge from the interview data. For example, lesbian, gay, and bisexual participants in the study by Rivers (1999) were interviewed about a number of emotive issues, such as the process of 'coming out,' linked to social exclusion from the peer group both at school and the workplace. The procedure for analyzing the interview transcripts as recommended by Frontman and Kunkel (1994) was as follows: (i) scrutiny of transcripts; (ii) open coding; (iii) axial coding; (iv) selective coding; and (v) integration. Rivers demonstrated that participants could also be interviewed using this method for experiences of being bullied at work.

In some companies, it is policy for HR staff to interview all employees at the point of departure. Such interviews could be based on the EVLN model (Withey \& Cooper, 1989) which suggests four final reactions when people are unhappy at work - exit (E), voice (V), loyalty $(\mathrm{L})$, or neglect $(\mathrm{N})$. Employees can leave their job (E); try to improve their situation 
through active problem-solving (V); they can passively hope that the organization will solve the problem for them (L); or they can focus attention on non-work interests $(\mathrm{N})$. We argue that, with the cooperation of HR and the permission of the employee, researchers could interview those on the point of leaving, and also interview a sample of those who claim to have been victimized and a control group of those who are leaving for other reasons. However, exit interviews may present reliability and validity problems since they could form one way for the disgruntled employee to get revenge or cause trouble without any danger of repercussion from the company.

Compared to questionnaires, interviews are responsive to the unique nature of each bullying situation. Thus, they are particularly suited to obtaining in-depth material on the nature of bullying and participant's experiences, and a standard interview format can be used. So, Rivers (1999) was able to access extremely sensitive material from his participants by asking open-ended questions about respondents' experiences of intolerance or harassment at work. Each section of the interview was prefixed by a short discussion about the issues to be covered and offered participants the opportunity to raise any concerns they had about answering certain questions. Each interview lasted between 60 and 90 min and was recorded on audiotape. There was a debriefing session of $30 \mathrm{~min}$ at the end. Overall, the interviews demonstrated that work or university could be a much more positive experience for lesbians, gay men, and bisexual people than previously reported in the literature. Positive experiences at work or university were the result of a combination of factors: at one level, their determination not to be victimized again; however, at another level, they also sought out 'gay-friendly' environments in which to work or remained 'closeted' until they were sure of colleagues' attitudes towards homosexuality. This led to the interesting finding that success as a lesbian, gay, or bisexual adult was as much about caution and good judgement, as it was about personal strength and determination. A major criticism would be, of course, that the sample was extremely small (only 16 in this study) due to the timeconsuming nature of this approach, and it is clear that the interview method is not suitable for large-scale analytic studies.

\subsection{Personal accounts elicited through focus groups}

Interviews can also be carried out in focus groups. Focus groups typically bring $8-12$ people together for a roundtable discussion lasting from 1 to $2 \mathrm{~h}$. The participants are selected because they share certain characteristics that are relevant to the study; usually they do not know one another before the group meets. The technique of interviewing participants in focus groups is widely used in marketing research as an exploratory research method to help companies gain a deeper understanding of their customers' perceptions, feelings, motivations, and desires. The method has been used specifically to elicit perspectives on workplace experiences of bullying by Liefooghe and Olafsson (1999). Focus groups are also a means of gathering in-depth, qualitative information about opinions and attitudes on a wide range of issues.

The interviewer asks focused questions to encourage discussion and the expression of differing points of view, and must be skilled in eliciting the participants' self-disclosure through the creation of a permissive environment. The format allows the exploration of 
unanticipated issues as they arise in the discussion. A number of techniques may be used to elicit the participants' ideas and experiences, including facilitating questions (e.g., asking for clarification of an opinion offered by a participant), vignettes (e.g., experiences of adults in other workplace settings), or eliciting personal constructs (e.g., laddering).

Wilson (1997) recommends the method since it gives the researcher an opportunity to hear the stories that emanate from a group, and demonstrates a greater variety of discourse than other methods (with the exception of naturalistic observation). Interviews are carried out with several groups so that the interviewer can identify trends in the perceptions and opinions expressed. This not only assists confidentiality and reduces bias, but also provides valuable information through allowing comparisons between groups.

Focus groups provide a useful method for getting responsive data on the nature of bullying at an organizational level. They are less time-consuming than an equivalent number of individual interviews, but care must be taken that the outcome of the focus group is not unduly influenced by a few individuals, or — as can happen — by having individuals 'planted' in the focus groups by management. There are also ethical difficulties concerning the use of focus groups in this area. If focus groups are conducted in one organization, it must be large enough so that members of the focus group do not come from the same work group or team and preferably not from the same functional area. They should not know one another nor have normal contact at work. This is because the information elicited through the focus group is likely to be highly charged. In many arenas, either the behavior under discussion is illegal or has the potential for putting the organization at risk of civil complaints. The researcher must be aware that even the reassurance that everything said during the focus group will be treated confidentially cannot be guaranteed, and that focus group comments are likely to have a life beyond the focus group interview room (for example, the material gathered in focus groups could be subject to misuse in court). Potentially, this could have an impact on the organization or at least on certain individuals within it, so there would be strong pressures in the individual to be extremely guarded in anything that they might disclose. One solution would be to use focus groups with participants recruited from a wide range of organizations and to see this method as simply a useful first stage before moving to a questionnaire/survey design, in order to maximize the validity of the data obtained from the latter, and the validity (external and internal) of the instrument.

\subsection{Critical incident technique}

CIT (Flanagan, 1954; Lewis, 1992) is a job analysis technique that focuses participants on a particular scenario. Flanagan used the method to analyze failure in military flying training during the Second World War. Liefooghe and Olafsson (1999) used Lewis's adaptation of CIT by asking participants to describe hypothetical individuals who are 'extremely like ... bullies' and those who are 'not at all like ... bullies.' The aim of the research was to investigate bullying as a social and cultural phenomenon, that is, one that was experienced not only by a 'bully' and a 'victim,' but also by a whole group or even by a culture at large. Forty participants (university staff and students) were interviewed in focus groups in order to elicit representations of the phenomenon through discussion. The researchers claim that through the process of exploring people's representations of bullying at work they were able 
to gain understanding of the different individual and organizational factors that influence the emergence of the concept of bullying into the social domain.

For example, in the study by Liefooghe and Olafsson (1999), participants engaged in a form of negotiation about the actual nature of the behavior that they tentatively defined as bullying, and indicated the realization that bullying often came gradually. The researchers conclude that bullying is not so much an objective reality as a set of events that can be conceptualized in many ways. By studying the phenomenon using methods such as CIT, they argue, researchers can gain access to personal and organizational meanings of the phenomenon. Critical factors are that the sample is quite small (44 individuals in five focus groups), the views expressed may have been influenced by dominant individuals in the focus groups, and the researchers' conclusions may go far beyond the information given. In fact, there is no evidence given of inter-rater reliability in the interpretation of the material that was elicited.

Overall, an advantage of this method is that it can provide a framework for studying bullying at different levels in a company. A disadvantage is that it is time-consuming to gather data, the material tends to be very open-ended and so hard to categorize systematically, and there is the danger of obtaining accounts that are biased in a particular way. The difficulties identified earlier in the focus group method would also apply to CIT as administered in these studies.

\subsection{Bubble dialogue}

The idea of bubble dialogue is derived from Rosenweig, Fleming and Clarke's (1947) Picture-Frustration Study, a projective technique for eliciting patterns of response to test material consisting of unrelated 'cartoon-like pictures in each of which two persons are involved in a frustrating situation of common occurrence' $\mathrm{p}$. 165. In each cartoon, one of the characters is describing the frustration and the other is shown with a blank 'think' box that the respondent is asked to complete. In a similar way, bubble dialogue (O’Neill \& McMahon, 1990) presents participants with a comic strip story and asks them to imagine what they think some of the characters in each scene are thinking by completing empty 'think' bubbles. The ecological validity of the method can be strengthened by obtaining a real-life story from an independent sample of participants who are drawn from the same population as the intended test sample. The ensuing dialogue reveals the perceptions that participants bring to the ongoing interaction. Data can be analyzed qualitatively (Glaser \& Strauss, 1967; Strauss \& Corbin, 1990) or quantitatively through content analysis. The data derived by this method can be subjected to test-retest reliability assessment and to the inter-rater reliability assessment of the scoring.

Bubble dialogue has been used to investigate adolescents' (Naylor, 1999) and trainee teachers' (Cohen, 1993) perceptions of teacher racism. Although the researchers carried out inter-rater reliability tests on the scoring, they did not use the qualitative responses gained to explore individuals' thoughts and feelings across the range of types of bullying identified earlier nor did they use the cartoons to investigate participants' ideas about the frequency and duration of the phenomenon. Respondents had the opportunity to take the role of different people in a bullying situation and be free of the constraints that they might feel in real-life situations (Cunningham et al., 1991). So, although the method has the advantage of being non-threatening, especially to people with low levels of literacy, the scoring has not been 
systematically developed for replication and there is no evidence that responses are reliable or that they have validity in this domain.

\section{Measures of workplace bullying 2: outside perspectives on the experience of bullying}

\subsection{Observational methods}

Observational methods can be applied to the study of human relationships in real world settings, through the use of audio- and video-recordings, and scrutiny of documentation from HR. Hinde (1996) emphasizes the importance of studying people in their natural settings. He identified the following dimensions for studying human relationships: the content of interactions making up the relationship, the diversity of these interactions, the quality of these interactions, the frequency and patterning of these interactions, the reciprocity or complementarity of these interactions, the intimacy of information that is given to the other person, the interpersonal perceptions of those involved in the interaction, and the amount of commitment. Hinde has stressed the need to develop a descriptive base of naturally occurring interpersonal relationships that will allow the researcher to compare and contrast the nature and quality of different types of interaction.

Applying this approach to the workplace, Neuberger (1996) asserts that interpersonal relationships in organizations display certain characteristics. They are embedded in a wider social context that is efficiency-oriented, in which there is a general motivation through pay, and where there is a scarcity of, and competition for, resources, whether of tools, finance, information, or time. As Neuberger argues, under these framing conditions, the nature of 'colleague relationships' is based on the design of the context in which they are embedded. So encounters and relationships in these contexts are unavoidable and, at the same time, demand the suppression of some aspects of personal identity (for example, intimate relationships) and agreement to a form of role conformity (for example, hierarchical management structures).

Despite the difficulties, there are precedents in applying the observational approach to the study of bully-victim relationships, particularly in schools. In research by Craig and Pepler (1995) into bullying in the playground, pupils, with the permission of their parents and teachers, agreed to have radio-microphones attached to them during break times, and to be filmed. This material was analyzed for verbal and non-verbal interaction. Although adults are more sensitive than children about being watched and despite the fact that there could be legal constraints on using such methods in workplace settings, some investigators have used observational methods to study aggressive acts in the workplace. For example, Palmstierna and Wistedt (1987) designed the Staff Observation Aggression Scale (SOAS) to monitor aggressive behavior in psychiatric wards. It was later revised by Nijman et al. (1999) as the SOAS-R. The scale assesses the nature and severity of aggressive acts on psychiatric wards, and has been widely used in descriptive studies and in the evaluation of interventions in that context. Evidence of reliability has been found, in a correlation of .60 between SOAS-R severity scores for outwardly directed aggression and scores on a rating scale of aggressive acts filled in by hospital staff members. 
The advantage of observational methods is that the researcher gains access to real-life, authentic interactions as they occur. However, observational data - especially those on videotape - can be very time-consuming to analyze; and the data usually represent only a subset of all workplace interactions. Furthermore, there are ethical issues and practical constraints around using this kind of material for research purposes.

\subsection{Peer nomination methods}

The peer nomination method has been often used to identify bullies and victims in schools contexts. Each member of a class is asked to nominate classmates; most commonly, those who are bullies, or victims. This yields four categories: bullies, victims, bully/victims (both), and controls (neither) (e.g., Bowers et al., 1994). In a more elaborated scheme, Salmivalli (1998) and Salmivalli, Lagerspetz, Björkqvist, Österman, and Kaukiainen (1996) developed the Participant Role Scale (PRS) to describe the bullying process among 12-13year-old Finnish school children. The roles nominated by peers were: victim, bully, reinforcer of the bully, assistant to the bully, defender of the victim, and outsider. The peer nomination method (including the PRS) could be modified to investigate the context of workplace bullying; and possibly an even further elaborated scale of roles could be developed for an adult population.

The advantage is that the material could offer access to the perspectives of employees with recent experience of involvement in bullying episodes, whether as victims, bullies, or bystanders. Reliability could be argued to be high, in terms of the pooling and comparing of perspectives of many work colleagues. A disadvantage is the very salient ethical issue related to the naming of peers in a range of participant roles; participants may withdraw consent to use the material, and companies/individuals might refuse to give permission or withdraw it during the research project; guaranteed access to this material could be difficult to obtain. The method is also very time-consuming.

\section{Integrative and multi-modal approaches}

\subsection{Case studies}

The intensive study of one case has played an important part in the development of theory and practice in the social sciences. Typically, the case study researcher observes the acts of an individual unit — a person, a family or a group, or a larger community or organization. In a good case study, the researcher has the opportunity to use a wide range of sources of evidence, interviewing different participants, recording accounts and narratives in the participants' own words, and also drawing on observations and other sources of evidence to probe and analyze intensively the many aspects that contribute to the identity of this unit.

Yin (1994) argues that both case studies and samples in experiments can be generalized analytically to theory. The well-conducted case study can generate new hypotheses and research questions about the wider population to which this unit belongs. 
Adams (1992) and Crawford (1997) documented case studies of workplace bullying. Adams stressed the high cost of bullying and aggression in the workplace. She documented high rates of sickness and absenteeism, low morale, reduced productivity, high turnover of staff, damage to mental and physical health, and a poor company ethos. Crawford, a psychotherapist working with bullies, victims, and organizations, identified personality aspects to the problem. He linked the presence of bullying behavior to unresolved childhood conflicts in the individual that manifest themselves through difficulty in dealing with frustration and stress at work. These case studies would have benefited from being more rigorously analyzed. Adams' work, though pioneering, was not scientific and relied on anecdotal evidence gathered from self-selected volunteers, mainly victims. Crawford did not combine interviews, observations, and other sources of information but relied on his own global perceptions of interactions in certain workplaces, and his clinical experience as a psychotherapist treating victims of workplace bullying.

The advantages of the well-designed case study method are the material is open-ended, rich, and illuminating; in terms of power, the interviewer/interviewee relationship is more evenly balanced than it is in the questionnaire method; the method explores informants' lived experience; it enables the researcher to identify different types of bullying in depth; to have information on which persons were involved, what they did, who intervened, how the participants coped; discourse analysis can reveal inconsistencies, incoherence, or lack of meta-cognition in 'dishonest,' 'denying,' or 'idealizing' interviews. The case study method can also triangulate different methods and a range of perspectives and sources of evidence. The disadvantage is that the method is time-consuming, since it is usually only possible to investigate small samples of participants.

\subsection{Multi-modal approaches}

The adoption of multi-modal approaches may deepen our understanding of the complex phenomenon of workplace bullying in order to address the wide range of research questions currently being asked. Robson (1993) argues that 'real world' research requires that the researcher become immersed in the culture in order that 'persistent observation' and 'prolonged involvement' be achieved. Furthermore, through the integration of a range of methods and through 'triangulation' with data from other sources, the researchers can confirm or challenge the detail of particular findings. Clearly, it is of great importance to have available a range of methods. For one thing, the number of participants in workplace bullying varies widely (Höel et al., 1999; Niedl, 1996), depending on the source of data (for example, whether from self-reports or peer nominations), the time under consideration (whether in the present or during the participants' entire work experience), how long the attacks last (for example, 'now and then' or 'weekly'), their frequency, and the perceived imbalance of power. For another, over-reliance on the perspective of one group can blind the researcher to the wider view and inhibit a multi-faceted model of the causes of bullying (Zapf, 1999). So, from the range of methods presented here, we argue that it is necessary to triangulate research findings in order to take account of the nature, incidence, and multiple causes of bullying.

In recent years, there has been a move away from the idea that the researcher may be in a position to uncover 'one truth' through scientific investigation (e.g., Gergen, 1999). Rather, 
there are many perspectives that may be elicited through observations, self-reports, reflections on these observations and self-reports, conversations, and dialogues. In the field of workplace bullying, researchers have become progressively interested in the tools of alternative paradigms and have become more willing to combine methods from different methodologies in order to gain an understanding of the phenomena under investigation. Naturalistic and phenomenological approaches are being used to complement tests, surveys, and structured interviews. Furthermore, it is now more likely to be acknowledged that the researcher who investigates the phenomenon of bullying is not so much a detached, neutral observer as one who elicits different narratives from the various actors and participants in the everyday drama of the workplace (Czarniawska, 1998). In some contexts, the dominant story in the workplace may be based on rejection of those persons perceived as unworthy or different. In others, the dominant story may be based on collective admiration of those who are perceived as strong or manly. In others, the dominant story may be based on notions of fairness and justice. From this perspective, the researcher needs to take account of organizational stories, must document how they are constructed and interpreted by participants, and must note who tells the stories and in what contexts. In this way, the researcher can enter into a form of dialogue with organizational practice at different levels from the individual, to the group, to the culture of the organization as a whole.

By integrating internal and external perspectives, researchers can put themselves at the interface between individuals, the accounts they tell, the observations of peers and managers, and the organizations where they work. By engaging in the interactive dialogues suggested by an integrative approach, members of a community can be encouraged to view labels, such as 'victim,' 'bystander,' or 'bully' as the products of social interaction across many levels of the organization, and to be aware of attempts to resist change.

Questionnaire methods have been the most common research tools for the investigation of workplace bullying to date, and they have certainly played an important part in identifying the problem, exploring its incidence and the different forms that it takes. But there are many aspects to the problem of workplace bullying, some of which are not easily captured by the questionnaire method. It is difficult to gain access to companies in order to carry out studies that focus on the organizational level, yet for the full picture such studies urgently need to be undertaken. As Höel et al. (1999) suggest, the more subtle area for investigation may be the implicit contract between employer and employee that influences expectations within a workplace but that is extremely difficult to assess. Although the scientist's focus is very different from, say, the focus of an organization assessing bullying in order to avoid litigation, awareness of such contextual issues will continue to be essential if the scientist is to penetrate the subtle processes involved.

New methods such as the ones described in this review have the potential to give researchers access to a wider range of perspectives that individuals have on the phenomenon, even if some of the techniques described here appear less rigorous than traditional surveys and questionnaires. Principally, they provide the means to consider in greater detail the contexts, both physical and social, in which employees bully and are bullied, and to identify in rich, subtle ways the elusive characteristics of the phenomenon that can be lost in largescale quantitative studies. Organizations are not homogeneous systems, and activities in workplace settings may evoke various, and sometimes conflicting, accounts of events and 
experiences. Researchers should make clear the extent to which their investigations have taken account of the interaction of participants, events, and contextualizing environment to illuminate the phenomenon of bullying. In particular, we argue that, by integrating inside and outside perspectives on the problem and by using a range of research methods, researchers may develop keys to unlock the barriers that prevent us from reducing a serious interpersonal and organizational problem that causes such misery for individuals and that undermines effective working relationships in contemporary society.

\section{Acknowledgments}

We would like to acknowledge the contribution of colleagues who met to discuss the content of a report to the EU Training and Mobility of Researchers (TMR) project (1999) 'The causes and nature of bullying and social exclusion in schools and the workplace': Lucy Bradshaw (Goldsmiths College), Sari Kaipiainen (Goldsmiths College), Andy Liefooghe (University of Surrey Roehampton), Ragnar Olafsson (Institute for Educational Research, Reykjavik, Iceland), Charlotte Rayner (University of Staffordshire), and Mechthild Schåfer (University of Munich). We are also grateful to the two anonymous reviewers for their constructive and detailed commentaries that have been incorporated into the final version of this article.

\section{References}

Adams, A. (1992). Bullying at work: how to confront and overcome it. London: Virago.

Almeida, F. N. (1992). Comportamentos de sucesso - Psicologia aplicada à Gestão (pp. 137-224). Lisboa: McGraw-Hill.

Baron, R., Nauman, J., \& Geddes, D. (1999). Social and personal determinants of workplace aggression: evidence from the impact of perceived injustice and the type A behavior pattern. Aggressive Behavior, 25, 281-296.

Björkqvist, K., Österman, K., \& Hjelt-Bäck, M. (1994). Aggression among university employees. Aggressive Behavior, 20, 173-184.

Björkqvist, K., Österman, K., \& Lagerspetz, K. (1994). Sex differences in covert aggression in adults. Aggressive Behavior, 20, 27-33.

Bowers, L., Smith, P. K., \& Binney, V. (1994). Perceived family relationships of bullies, victims and bully/victims in middle childhood. Journal of Personal and Social Relationships, 11, 215-232.

Brodsky, C. (1977). The harassed worker. Lexington, MA: D.C. Heath and Company.

Cohen, L. (1993). Racism awareness materials in initial teacher training. Report to the Leverhulme Trust, London.

Cowie, H., Bradshaw, L., Kaipiainen, S., Liefooghe, A., Naylor, P., Olafsson, R., Rayner, C., Rivers, I., Schåfer, M., \& Smith, P. K. (1999). Report of the Training and Mobility of Researchers (TMR) Working Party: Adult Bullying. (http://www.gold.ac.uk.tmr) (EU Training and Mobility of Researchers (TMR) Website).

Coyne, I., Seigne, E., \& Randall, P. (1999). Personality traits as predictors of workplace bully-victim status. In: Proceedings of the British Psychological Society Occupational Psychology Conference (pp. 193-198).

Craig, W., \& Pepler, D. (1995). Peer processes in bullying and victimisation: an observational study. Exceptionality Education Canada, 5, 81-95.

Crawford, N. (1997). Bullying at work: a psychoanalytic perspective. Journal of Community and Applied Social Psychology, 7, 219-226.

Crick, N., \& Grotpeter, J. (1995). Relational aggression, gender and social-psychological adjustment. Child Development, 66, 710-722. 
Cunningham, D., McMahon, H. J., \& O'Neill, W. (1991). Bubble dialogue: a new tool for instruction and assessment. Educational Technology, Research and Development, 40, 59-67.

Czarniawska, B. (1998). A narrative approach to organization studies. London: Sage.

Einarsen, S., \& Raknes, B. (1991). Mobbing I arbeitslivet. En unsokerelse av forekomst og helsemessige konsekvenser av mobbing på norske arbeidsplasses. Bergen: FASH Universitetet i Bergen.

Einarsen, S., \& Raknes, B. (1997). Harassment in the workplace and the victimisation of men. Violence and Victims, 12, 247-263.

Einarsen, S., Raknes, B., \& Matthiesen, S. B. (1994). Bullying and harassment at work and their relationships to work environment quality: an exploratory study. European Journal of Work and Organizational Psychology, 4, $381-401$.

Einarsen, S., \& Skogstad, A. (1996). Bullying at work: epidemiological findings in public and private organizations. European Journal of Work and Organizational Psychology, 5, 185-201.

Fitzgerald, L. F., Swan, S., \& Magley, V. J. (1997). But was it really sexual harassment? In: W. O. O’Donohue (Ed.), Sexual harassment: theory, research and treatment. Boston: Allyn and Bacon.

Flanagan, J. C. (1954). The critical incident technique. Psychological Bulletin, 51, 327-358.

Frontman, K. C., \& Kunkel, M. A. (1994). A grounded theory of counselors' construal of success in the initial session. Journal of Counseling Psychology, 41, 492-499.

Gergen, K. (1999). An invitation to social construction. London: Sage.

Glaser, B. G., \& Strauss, A. L. (1967). The discovery of grounded theory. Chicago: Aldine.

Hinde, R. A. (1996). Describing relationships. In: A. E. Auhagen, \& M. von Salisch (Eds.), The diversity of human relationships. Cambridge: Cambridge Univ. Press.

Höel, H., Rayner, C. L., \& Cooper, C. (1999). Workplace bullying. In: C. L. Cooper, \& I. T. Robertson (Eds.), International review of industrial and organizational psychology, vol. 14. Chichester: Wiley.

Keashley, L., Trott, V., \& MacLean, L. M. (1994). Abusive behavior in the workplace. Violence and Victims, 9, $341-357$.

Lewis, C. (1992). Employee selection. Cheltenham: Stanley Thornes.

Lewis, D. (1999). Workplace bullying - interim findings of a study in further and higher education in Wales. International Journal of Manpower, 20, 106-118.

Leymann, H. (1990). Mobbing and psychological terror at workplaces. Violence and Victims, 5, 119-126.

Leymann, H. (1996). The content and development of mobbing at work. European Journal of Work and Organizational Psychology, 5, 165-184.

Liefooghe, A., \& Olafsson, R. (1999). "Scientists" and "amateurs": mapping the bullying domain. International Journal of Manpower, 20, 39-49.

Lima, M. L., Vala, J., \& Monteiro, M. B. (1994). A satisfação organizacional: confronto de modelos. In: J. Vala (Ed.), Psicologia Social das Organizações (pp. 101-122). Oeiras: Celta.

McGhee, P., \& Miell, D. (1998). Everyday experience of social interaction and relationships. D317: social psychology: personal lives, social worlds. Milton Keynes: Open Univ. Press.

Monks, C., \& Smith, P. K. (2000). Relationships of children involved in bully/victim problems at school. In: R. Mills, \& S. Duck (Eds.), Developmental psychology of personal relationships (pp. 131-153). Chichester: Wiley.

Monteiro, M. B. (1993). Conflito e cooperação nas relações intergrupais. In: J. Vala, \& M. B. Monteiro (Coords.), Psicologia Social (pp. 309-352). Lisboa: Fundação Calouste Gulbenkian.

Naylor, P. (1999). Adolescents' conceptions of teacher racism: an investigation using bubble dialogue as a research tool. Research in Education, 61, 85-87.

Neuberger, O. (1996). Relationships between colleagues. In: A. E. Augagen, \& von Salisch, M. (Eds.), The diversity of human relationships (pp. 269-288). Cambridge: Cambridge Univ. Press.

Niedl, K. (1995). Mobbing/Bullying am Arbeitsplatz. Eine empirische analyse zum Phanomen sowie zu personal/ wirtschaftlich relevanten Effecten von systematischen Feindseligkeiten. Munchen: Rainer Hampp Verlag.

Niedl, K. (1996). Mobbing and well-being. European Journal of Work and Organizational Psychology, 5, 239-249.

Nijman, H., Muris, P., Merckelbach, H., Palmstierna, T., Wistedt, B., Vos, A., van Rixtel, A., \& Allertz, W. (1999). The Staff Observation Aggression Scale Revised (SOAS-R). Aggressive Behavior, 25, 197-209. 
Olweus, D. (1993). Victimisation by peers: antecedents and long-term outcomes. In: K. H. Rubin, \& J. B. Asendorf (Eds.), Social withdrawal, inhibition and shyness. Hillsdale, NJ: Erlbaum.

Olweus, D. (1999). Sweden. In: P. K. Smith, Y. Morita, J. Junger-Tas, D. Olweus, R. Catalano, \& P. Slee (Eds.), The nature of school bullying: a cross-national perspective (pp. 7-27). London: Routledge.

O’Neill, W., \& McMahon, H. J. (1990). Opening new windows with bubble dialogue. Coleraine, Ulster: Language and Hypermedia Research Group, University of Ulster.

Palmstierna, T., \& Wistedt, B. (1987). Staff observation aggression scale: presentation and evaluation. Acta Psychiatrica Scandinavia, 76, 657-663.

Quine, L. (1999). Workplace bullying in NHS Community Trust: staff questionnaire survey. British Medical Journal, 318, 228-232.

Randall, P. (1997). Adult bullying: perpetrators and victims. London: Routledge.

Rayner, C. (1997). The incidence of workplace bullying. Journal of Community and Applied Social Psychology, 7 , 199-208.

Rayner, C., \& Höel, H. (1997). A summary review of literature relating to workplace bullying. Journal of Community and Applied Social Psychology, 7, 181-191.

Rivers, I. (1999). The psycho-social correlates and long-term implications of bullying at school for gay, lesbian and bi-sexual adults. Unpublished PhD Thesis, University of Surrey Roehampton.

Robson, C. (1993). Real world research: a resource for social scientists and practitioner-researchers. Oxford: Blackwell.

Rosenweig, S., Fleming, E. E., \& Clarke, H. J. (1947). Revised scoring manual for the Rozenweig PictureFrustration Study. Journal of Psychology, 24, 165-208.

Salmivalli, C. (1998). Not only bullies and victims: participation in harassment in school classes: some social and personality factors. Published PhD Thesis, University of Turku, Finland.

Salmivalli, C., Lagerspetz, K., Björkqvist, K., Österman, K., \& Kaukiainen, A. (1996). Bullying as a group process: participant roles and their relations to social status within the group. Aggressive Behavior, 22, 1-15.

Schuster, B. (1996). Rejection, exclusion and harassment at work and in schools. European Psychologist, 1, $293-317$.

Sheehan, M. (1998). Restructuring — rhetoric versus reality. In: P. McCarthy, M. Sheehan, S. Wilkie, \& W. Wilkie (Eds.), Bullying: causes, costs and cures. PO Box 196, Nathan Qld 4111, Australia: The Beyond Bullying Association.

Smith, P. K. (1997). Bullying in life-span perspective: what can studies of school bullying and workplace bullying learn from each other? Journal of Community and Applied Social Psychology, 7, 249-255.

Sousa, F. H., \& Vala, J. (1999). Justiça nas organizações. O modelo do valor do grupo e as orientações comportamentais face à mudança. Psicologia, XIII (1-2), 25-52.

Strauss, A., \& Corbin, J. (1990). Basics of qualitative research: grounded theory procedures and techniques. Newbury Park, CA: Sage.

Theotónio, S. A., \& Vala, J. (1999). A experiência de justiça e de injustiça nas organizações: um estudo quantitativo. Psicologia, XIII (1-2), 53-73.

Trades Union Congress (TUC). (1998). Beat bullying at work: a guide for trade union representatives and personnel managers. Congress House, Great Russell Street, London WC1B 3LS: TUC.

Wilson, V. (1997). Focus groups: a useful qualitative method for educational research? British Educational Research Journal, 23, 209-224.

Withey, M., \& Cooper, W. (1989). Predicting exit, voice, loyalty and neglect. Administrative Science Quarterly, 34, 521-539.

Yin, R. (1994). Case study research. Thousand Oaks, CA: Sage.

Zapf, D. (1999). Organizational, work group related and personal causes of mobbing/bullying at work. International Journal of Manpower, 20, 70-84.

Zapf, D., Knortz, C., \& Kulla, M. (1996). On the relationship between mobbing factors and job content, social work environment, and health outcomes. European Journal of Work and Organizational Psychology, 5, $215-237$. 